

\section{A cozinha pós-moderna do MasterChef Brasil: Social TV e mídia que se propaga no Twitter}

\section{The post-modern kitchen of MasterChef Brazil: Social TV and spreadable media on Twitter}

Mateus Dias Vilela' $\boldsymbol{C}$

Tauana Mariana Weinberg Jeffman' $[3$

\section{Resumo}

As redes sociais têm servido como ágoras na qual os indivíduos, em torno de conteúdos televisivos, reúnem-se dando origem ao fenômeno de Social TV. Dessa forma, a televisão busca se adaptar a um novo cenário audiovisual ao criar conteúdos que se propagem e incitem a discussão e o compartilhamento. Diante deste contexto, este ensaio analisa o reality show MasterChef Brasil, ao perceber que este propagou-se ao potencializar o papel da Social TV e ao empoderar seu público presente no Twitter.

\section{Palavras-chave}

Televisão; Social TV; Twitter; propagação.

\section{Abstract}

Social media have served as agoras in which individuals, around television content, meet giving rise to the Social TV phenomenon. Thus, television seeks to adapt to a new audiovisual scene to create content that propagate and incite discussion and sharing. Given this context, this paper analyzes the reality show MasterChef Brasil, realizing that this show has spread the Social TV and empower your audience on Twitter.

\section{Keywords}

Television; Social TV; Twitter; propagation.

54 PORTO ALEGRE | v. 20 | n. 34 | 2015 | pp. 54-62 DOl: http://dx.doi.org/10.15448/1980-3710.2015.2.21984 Sessões do Imaginário 


\section{Introdução}

A forma com que os indivíduos se enxergam e relacionam-se, seja consigo mesmos ou com os outros, mudou. As percepções de tempo e espaço, religião, comunidade, trabalho e comunicação também sofreram uma série de alterações, que podem ser entendidas pelo período em que vivemos: a pós-modernidade. O pós-moderno, ao corrigir alguns excessos da modernidade, abandonou os exageros individualistas e racionalistas, moldando uma sociedade que precisa do outro, mais ainda, se satisfaz no outro. Essa necessidade de estar em constante conexão, Michel Maffesoli (1998) chama de retribalização ${ }^{3}$ do mundo, que é potencializada pela cibercultura, onde o social e o aparato tecnológico congregam, potencializando a socialidade (Lemos, 2010).

A cibercultura atua, como facilitador, ao permitir que os indivíduos busquem por suas tribos, no momento em que podem capturar somente aquilo que lhes é interessante. Não obstante, esse movimento provocou o que Elizabeth Saad e Marcelo Coutinho (2009) chamam, de crise dos media tradicionais que atinge, ainda, uma das mídias massivas mais tradicionais e influentes da sociedade, a televisão.

Ao passar pelo processo de digitalização, uma série de mudanças foram impressas ao meio, acarretando transformações profundas nas formas de produção e recepção televisivas, que vão desde uma melhoria na qualidade de som e imagem até a possibilidade de interação e personalização do conteúdo. A digitalização está alterando a essência das mídias. Algumas estão tornando-se propagáveis. Outras, no entanto, insistem em se manter extremamente tradicionais, arriscando perder um público que está a cada dia mais "sempre ligado"4

\section{Mídia que se propaga}

Através das palavras de Henry Jenkins, Joshua Green e Sam Ford (2014), entendemos os meios de comunicação tradicionais como componentes do que os autores intitulam de "mídia mainstream", que se diferenciam da "mídia propagável". Acreditamos que esta diferença entre características de mídia é aporte fundamental para compreender nosso objeto, o MasterChef, em comparação a outros programas que não possibilitam, ou não permitem, a participação efetiva do público. Entender os princípios da mídia propagável é também entender por que um conteúdo se espalha nas redes sociais e outros não. O que influencia na decisão do público no momento em que este compartilha uma notícia em seu Facebook ou posta um tweet em seu Twitter. Tais decisões; como sabemos, "estão remodelando o próprio cenário da mídia" (Jenkins; Green; Ford, 2014, p. 25).

Para que uma mídia, ou um conteúdo, torne-se propagável, é imprescindível que recursos técnicos sejam disponibilizados para tais fins, facilitando sua circulação. O objetivo da mentalidade propagável é criar conteúdos que "vários públicos possam espalhar por diferentes motivos, convidando as pessoas a moldar o contexto do material conforme o compartilham no âmbito de suas redes sociais" (Jenkins; Green; Ford, 2014, p. 29). Percebemos, então, que neste cenário o público desempenha um papel ativo na propagação dos conteúdos. São os seus valores, interesses e propósitos que definem o que tem valor ao ponto de merecer ser propagado. Quando a mídia se propaga, ela não somente consegue alçar novos voos e encontrar novos ares, como também promover um profundo engajamento nas comunidades de nicho (Jenkins; Green; Ford, 2014, p. 48).

É importante enfatizarmos a importância do público neste processo, pois todo material propagado é refeito.
Seja de modo figurado, quando o conteúdo é inserido em conversas por meio de diversas plataformas; ou de modo literal, quando o conteúdo é sampleado 5 ou remixado. Logo, o público não é apenas mais um dado no processo da comunicação. Ele é um propagador e um gerador de conteúdo, em um mundo que vive profundas mudanças no modo de se comunicar. O público é peça essencial em um mundo onde o que não se propaga, morre ( Jenkins; Green; Ford, 2014, p. 234).

Mas o que torna uma mídia propagável, além da facilidade de acesso e compartilhamento de conteúdo por parte do público? Há cinco princípios básicos que tornam o conteúdo apto a ser propagado, segundo Jenkins, Green e Ford (2014, p. 246):

1. Disponível quando e onde o público quiser (o público precisa ter fácil acesso ao conteúdo);

2. Portátil (o público pode compartilhar um texto de mídia em diversas plataformas, como os links do YouTube, por exemplo);

3. Facilmente reutilizável em uma série de maneiras (o conteúdo deve ser rico o suficiente para gerar conversas, outras publicações ou até mesmo sampleamentos e remixagem);

4. Relevante para os vários públicos (relevância é fundamental e não pode ser restrita a um único grupo) e

5. Parte de um fluxo constante de material (o público deve ser constantemente nutrido com conteúdo relevante e que tenha sentido em um conjunto maior).

É interessante perceber que a propagação de um conteúdo dificilmente resulta da solicitação direta de uma empresa, um anunciante ou um produtor. A pro- 
pagabilidade se dá de forma orgânica, e é o público que toma esta decisão. Basta a tais empresas, anunciantes e produtores entenderem como se dá este processo, motivando e facilitando seu desenvolvimento. Contudo, nenhum esforço será útil se o texto de mídia criado não envolver as pessoas, fazendo com que estas se sintam tocadas e considerem que compartilhá-lo com seus amigos vale a pena, transmitindo seus valores e significados (Jenkins; Green; Ford, 2014, p. 249). Isso porque, os conteúdos que compartilhamos também expõem ao outro quem somos; auxiliando desta forma em nossos relacionamentos profissionais e pessoais. Como bem lembram Barbosa e Campbell (2006), aquilo que consumimos tanto expressa quanto constrói nossa identidade, e isso vale também para o nosso consumo midiático.

Neste cenário de mídia propagável, há o empoderamento do público, pois este passa a auxiliar na formatação do seu próprio "ambiente de mídia cotidiano". Mas para que isto de fato ocorra, é preciso que os criadores de conteúdo criem múltiplos pontos de acesso aos textos de mídia, para que eles se tornem propagáveis e se (re)configurem em diversos grupos e núcleos de conversas (Jenkins; Green; Ford, 2014, p. 357). A nossa cultura está tornando-se cada vez mais participativa, através deste empoderamento. O que não significa, contudo, que todos os públicos participarão desta formatação, pois como afirmam Jenkins, Green e Ford (2014, p. 358), "nem todo mundo tem permissão para participar, nem todo mundo é capaz de participar, nem todo mundo quer participar e nem todo mundo que participa o faz em igualdade de condições". Logo, para certa parcela do público, por mais que a mídia seja propagável, ela será consumida como mídia mainstream. Para o restante do público, esta mídia proporcionará produções, conversações, apropriações, downloads, uploads, remixagens, sampleamentos, incorporações e recirculação de conteúdo. Cada vez que o conteúdo for reconfigurado e compartilhado, poderá ser novamente recontextualizado por outros públicos e, assim, compartilhado novamente. Deste modo, a mídia se espalhará como um dente-de-leão, ao sabor do vento (Jenkins; Green; Ford, 2014, pp. 359-365).

Neste viés de mídia propagável, adentraremos em compreensões especificamente acerca da Social TV, uma das possibilidades de relação contemporânea entre televisão, redes sociais e seu público.

\section{Televisão e redes sociais na internet:}

o fenômeno de Social TV

A sapiência que a televisão sofreria mudanças não é uma ideia nova. Alvin Toffler, em 1980, no livro A terceira onda, já afirmava estarmos vivendo em um momento em que os meios não estavam ampliando sua influência, pelo contrário, eram obrigados a compartilhá-la com os demais através dos chamados "meios de comunicação desmassificados" (Toffler, 1980, p. 162). A TV estaria, então, instaurada em uma sociedade em rede, a mesma proposta por $\mathrm{Ma}$ nuel Castells (2000) no livro A sociedade em rede.

Um dos exemplos paradigmáticos, propostos por Carlos Scolari (2012), é a CNN, emissora de televisão norte-americana, que no começo da década de 1980 dividia a tela em várias camadas com informações diferentes, "com as suas características próprias, por exemplo, a polifonia e a fragmentação da tela". O autor ainda lista as particularidades dessa nova fase da televisão (Scolari, 2014):

- A crescente interação entre emissor e receptor, tornando a experiência mais próxima da adquirida entre usuários da internet;
- O empoderamento dos públicos nas decisões de o que, quando, como e onde assistir a um conteúdo;

- O uso da interatividade para customizar, reapropriar e decidir o resultado de narrativas;

- Os novos suportes para assistir TV, como computadores, tablets e celulares. Além da televisão móvel e portátil, em todo lugar;

- A prevalência da programação assincrônica, com oferta de vídeo sob demanda de programas completos ou fragmentados;

- A flexibilização entre os gêneros informativo e ficcional;

- O fim das fronteiras entre conteúdo e publicidade, dando origem a modelos comerciais não baseados em intervalos comerciais;

- A articulação da TV com outros meios interativos.

A convergência da expansão narrativa não envolve somente materiais e serviços produzidos comercialmente, circulando pelos meios tradicionais, afirma Dominique Maingueneau (2008). Pelo contrário, ela ocorre também quando as pessoas tomam o controle das mídias. "Entretenimento não é a única coisa que flui pelas múltiplas plataformas de mídia. Nossa vida, nossos relacionamentos, memórias, fantasias e desejos também fluem pelos canais da mídia" (2008, p. 45). Frank Rose (2011) acrescenta:

Não faz muito tempo que éramos espectadores, consumidores passivos dos meios massivos. Agora, com YouTube, blogs, Facebook e Twitter nós somos a mídia. Em um momento em que assistimos cada vez mais televisão, a maneira como assistimos está mudando. Filmes, comerciais de TV e séries são convites para participarmos de uma experiência de imersão em tais conteúdos (2011, p. 15, tradução do autorº). 
Eliseo Verón (2007) acredita que a televisão deixou de focar-se em si mesma e transferiu sua atenção aos públicos, prova disso é a proliferação do gênero reality show e a chegada de tecnologias que propiciam a interação dos usuários. Ao operar em tempo real, Yvana Fechine argumenta que a programação cria, antes de mais nada, uma experiência comum de assistir TV, entre todos que estão vendo simultaneamente. A similaridade e a simultaneidade de conteúdos proporcionada pelo modelo de broadcasting transforma o meio em uma instância que possibilita uma reunião das pessoas, agindo como um agregador social: "contribui para a construção e difusão de valores, de sentimentos de pertencimento e de identidades" (2014, p. 125).

Para Pablo Cesar e David Geerts (2012), essa interação existente entre telespectadores que, simultaneamente à apresentação de um programa na televisão, comentam nas redes sociais sobre algo que acabou de ser exibido é considerado uma ação de Social TV. Ou seja, é uma interação, além de uma socialização, de informações relativas a determinado conteúdo televisivo para os usuários da mesma rede social em que as postagens forem feitas. Em 2010, o Massachusetts Institute of Technology (MIT) já apontava tal fenômeno como uma tendência mundial (Bulkeley, 2010).

Sobre o conceito de Social TV é preciso esclarecer que não é a mesma coisa que segunda-tela. Segunda-tela não necessariamente significa que o usuário está, na internet, comentando sobre o que está vendo na televisão. Ou seja, toda experiência de Social TV será também de segunda tela, mas nem toda experiência de segunda-tela será Social TV.

Mike Proulx e Stacey Shepatin (2012) justificam tal fenômeno como fruto da curiosidade das pessoas. É a vontade de sempre ter conhecimento sobre tudo que está acontecendo ao seu redor.
O trampolim que impulsionou a ideia da aplicação da segunda tela como uma companheira da TV é baseado em um princípio simples: somos seres muito curiosos e compelidos a alimentar essa curiosidade. Quando estamos conectados a uma segunda tela enquanto vemos TV, temos acesso instantâneo para procurar uma quantidade infinita de informações sobre o programa a que estamos assistindo e, dessa forma, ajudamos a satisfazer nossa curiosidade natural (Proulx; Shepatin, 2012, p.58, tradução do autor').

Mark Johns (2012) faz referência ao uso de telas para a criação de um canal de fundo, em tempo real, entre o público de determinado programa. Uma combinação de tecnologias que permitem experiências sociais em torno da televisão, é a forma como Gunnar Harboe (2009) define a Social TV, dividindo-a entre conceitos restritos e amplos, como mostra o Quadro 1.

Como o próprio nome já alerta, o caráter social desse fenômeno é relevante. Segundo Marie-José Montpetit (et al., 2010), pesquisadora do MIT, a interação faz parte de toda a experiência televisiva. A Social TV decorreria de duas tendências ligadas intrinsecamente, a interação social e a personalização, agregando ainda dois comportamentos distintos, ativo e o passivo, no momento em que une a experiência passiva de entretenimento com a interação ativa da internet (Montpetit et al., 2010).

Com um entendimento bastante aproximado de Montpetit, Elissa S. Silva e Ana Silvia Médola (2013) acreditam que existem três motivações principais para o uso da Social $T V$ :a interação com o conteúdo, a socialização e a busca por informações e extras. Apesar de que todas essas instâncias já serem possibilitadas, em outros níveis, pelas emissoras, mas as redes sociais, indubitavelmente, as potencializaram. Raimund Schatz (et al., 2010) e Montpetit (et al., 2010) acres- centam, por fim, a questão da experiência compartilhada. Para os autores, as redes sociais possibilitam vivenciar situações de usos sociais da televisão. Experimentos revelaram que os indivíduos se engajam mais, através do contato com uma audiência virtual. Alguns usuários, segundo Jarno Zwaaneveld (2009), relataram assistir não somente seus programas favoritos, mas outros conteúdos somente pelo fato de outros o estarem fazendo. Afirmaram ainda que participavam de pequenas conversas sobre os programas durante o intervalo, compartilhando interesses em comum.

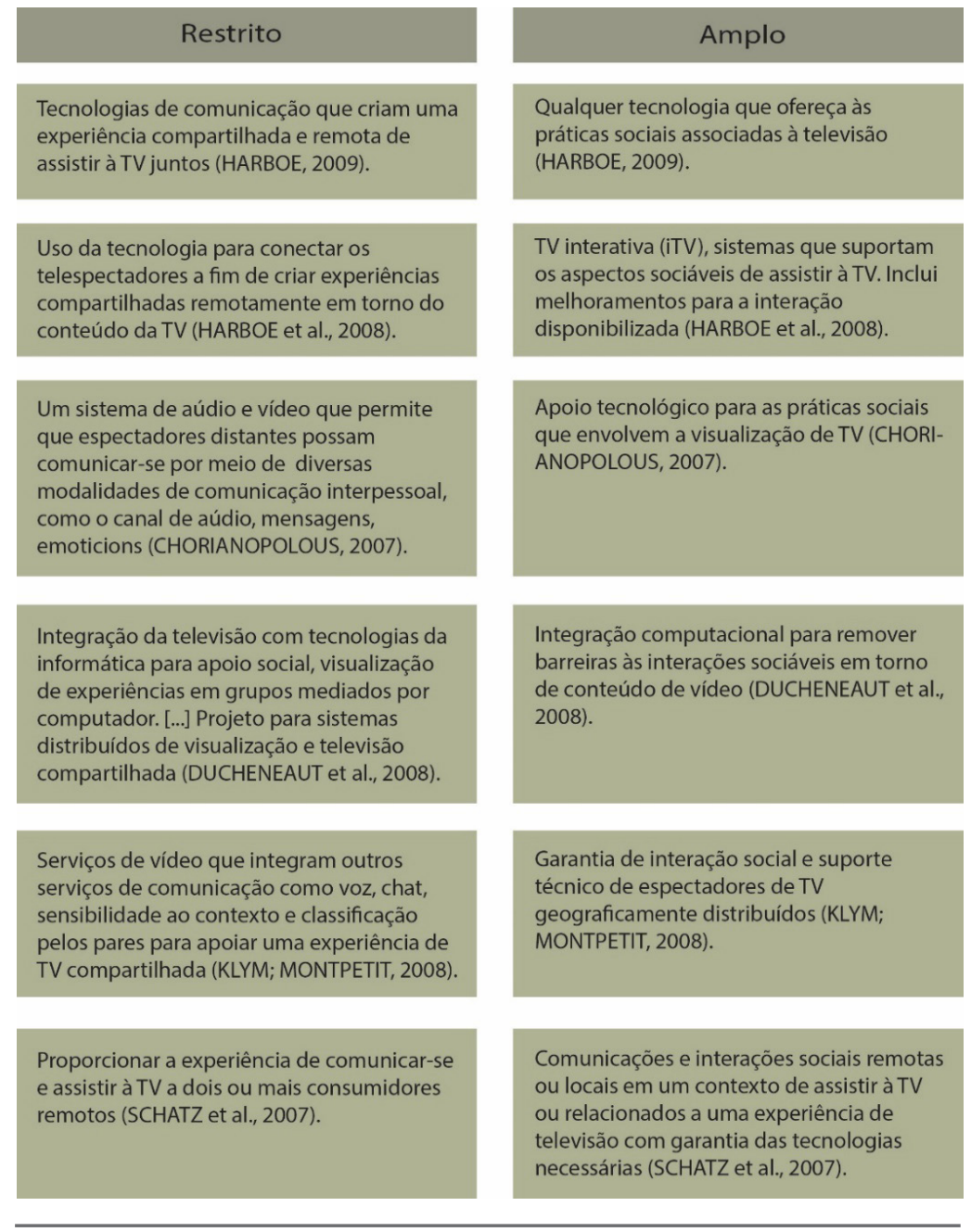

Quadro 1: Conceitos restritos e amplos sobre Social TV Fonte: Elaborado pelo autor com base em Harboe (2009). 
Trata-se, hoje, de uma conversa democrática e global que influencia o conteúdo dos programas e da publicidade. Ademais, um novo léxico foi incorporado ao meio das redes sociais. Expressões como spoiler ${ }^{8}$, season finale $^{9}$, hiatus ${ }^{10}$ e premiere ${ }^{11}$ foram adotadas por diversas culturas, mesmo as que não têm no inglês sua língua materna. Novos hábitos também entraram no ato de assistir televisão. A experiência de Social TV levou Montpetit (et al., 2010) a relacionar tal fenômeno com os primórdios da televisão. Para a autora, há uma redescoberta do ato de assistir TV como momento compartilhado, referenciando a décadas quando o meio ainda era bastante caro e, portanto, havia apenas um em cada residência.

Com o barateamento dos aparelhos e a possibilidade de cada cômodo possuir uma televisão, o ato de assistir TV foi tornando-se solitário, sendo redescoberto e potencializado, na pós-modernidade, pela cibercultura e as redes sociais. De acordo com Alex Primo (2010), o Twitter, mostra como a TV ainda é fonte de entretenimento:

Esse telespectador/twitteiro nos mostra que a televisão continua sendo uma opção de entretenimento. Por outro lado, não aceita mais a cômoda posição do sofá. Além de consumir o produto televisivo, ele quer ressignificar os conteúdos que recebe. Quer compartilhar suas opiniões e escutar o que os outros tem a dizer. Não o ruído de toda a massa, mas sim, o que pensam os participantes de suas comunidades (Primo, 2010, online).

O Twitter, segundo pesquisa TV Next Conference (Tanner, 2012), parece ser a rede preferida para a discussão sobre televisão. Dos usuários, 50\% publicam conteúdos sobre os programas que estão assistindo, contra $35 \%$ do
Facebook. Ainda assim, vale lembrar que em sua maioria os usuários que tem conta no Twitter, também possuem perfil no Facebook, mas preferem usar o microblog para tais usos de Social TV.

\section{Master Chef Brasil e o 'spoiler' \\ sobre si mesmo}

Criado por Franc Roddam, no Reino Unido, em 1990, o reality show culinário somente obteve sucesso no ano de 2005, ao ser atualizado e relançado pela BBC (BBC, 2015, online ${ }^{12}$ ). MasterChef é exportado para mais de 40 países e é transmitido em pelo menos 200 territórios. No Brasil, o formato estreou em 2014, encerrou em setembro sua segunda temporada, na Rede Bandeirantes, e é apresentado pela jornalista Ana Paula Padrão.

Apesar de ter obtido relativo sucesso na primeira temporada, foi na segunda, exibida em 2015, que o reality ganhou maior repercussão na televisão e nas redes sociais. Em dezessete semanas, o programa conquistou 274 milhões de tweets (Estadão, 2015, online ${ }^{13}$ ) somando somente os feitos de meia hora antes até duas horas depois da exibição do mesmo, gerando uma média de 304 mil tweets por episódio.

Em comparação com os dados da primeira temporada, em que a audiência teve média de 4,6 pontos, deixando a Band em quarto lugar, a segunda atingiu média de 7 pontos, levando a emissora a vice-liderança isolada. Com ações como enquetes e cronômetro de posts a emissora conseguiu engajar o público, como afirma Sérgio Floris, diretor de TV no Twitter.

A mensagem aqui é: quanto mais o canal de TV abre espaço para a audiência participar do programa recompensando-a na tela, com enquetes e outras ações, a chance de fidelizar esse público, fazendo com que aquilo se torne um evento para o telespectador, é cada vez maior. [...] A comunicação tem de ser muito clara, nada pode ser dúbio. [...] O diabo mora nos detalhes. Todo elemento vivo trazido para a tela é engajador, por mais que o conteúdo já esteja gravado (Estadão, 2015, online ${ }^{14}$ ).

Como em qualquer reality show, o principal ingrediente para o sucesso de uma temporada, é o elenco escolhido. Dessa forma, além das estratégias incitadas pela emissora, um dos grandes destaques no quesito de apropriações e menções, envolvem a terceira colocada, Jiang Pu, seja pela pronuncia errada de algumas palavras - ela é chinesa - seja pelos seus comentários sarcásticos, como mostra a Figura 1.

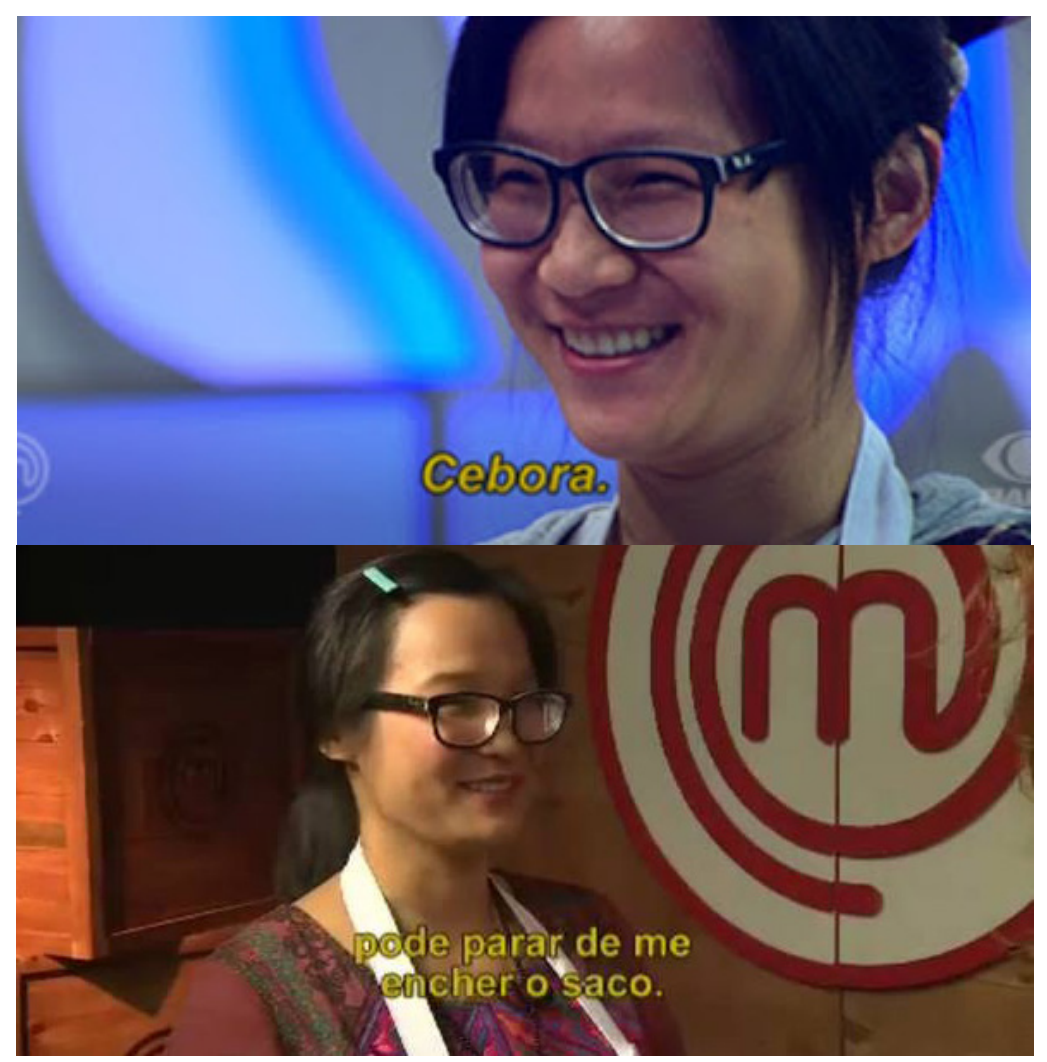

Figura 1: Apropriações envolvendo Jiang Pu. Fonte: Twitter.com.br AAGBNARI

58 PORTO ALEGRE | v. $20 \mid$ n. $34 \mid 2015$ | pp. 54-62 Sessões do Imaginário 


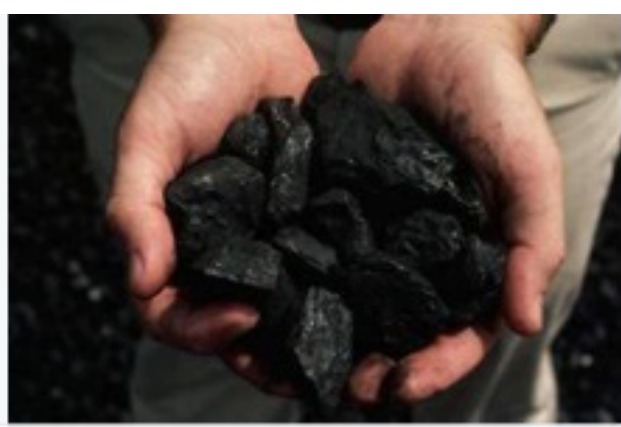

Eder Alex @EderAlex

tá na cara que a batata da jiang não queimou, o jurados é que são implicantes \#MasterChefBR

04: 04 - 9 set 2015

औ $\quad 2726 \quad \star 18$

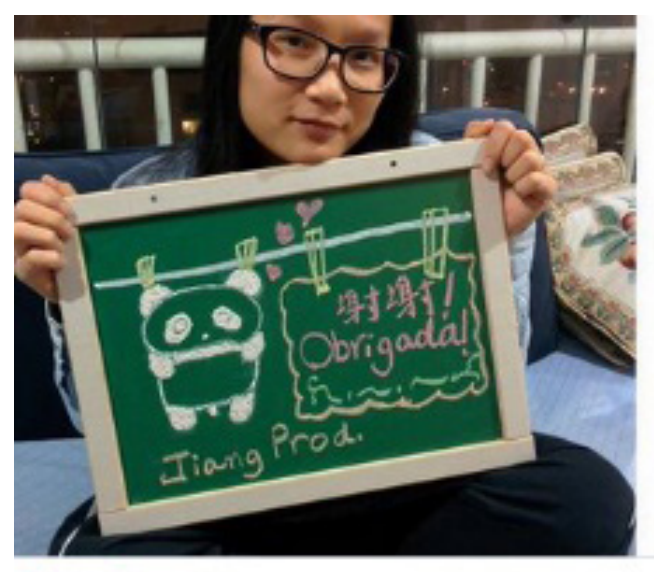

cleytu - @orincadero

"ganhei muito muito muito mais do que eu perde"

Jiang melhor pessoa $<3$

\#MasterChefBR

04: 41 - 9 set 2015

h $\quad 27847 \star 1.062$

Figura 2: Reações envolvendo a eliminação de Jiang Pu

Fonte: Twitter.com.br

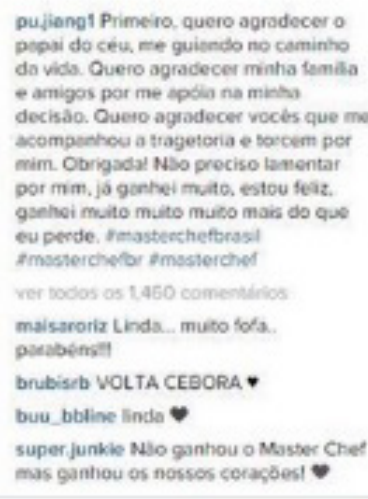

superf Junkie Nlo ganthou o Mustec Co

seguir
Por possuir grande torcida nas redes sociais, o dia da eliminação da participante, levou os usuários brasileiros a utilizaram a criatividade como forma de "protesto" contra a decisão dos chefs. Tal indignação gerou uma série de apropriações, majoritariamente visuais, com mensagens de apoio a Jiang, como mostra a Figura 2.

Diante de tamanha repercussão, a própria emissora decidiu por contratar a participante, para que ela faça parte da versão infantil do reality show que estreia no começo de 2016 (Band, 2016, online ${ }^{15}$ ). Entretanto, mesmo com o protagonismo de Jiang durante os episódios, foi na season finale que o Twitter foi declarado vencedor e verdadeiro protagonista do segundo clico da atração.

Enquanto o último episódio estava no ar, foi constante um contador de tweets, indicando a quantidade de menções ao programa no microblog, contabilizando aproximadamente 1,8 milhão de citações. Apesar de usar o contador em todos os capítulos, foi somente na finale que a apresentadora comemorou a marca de 1 milhão de menções, tal qual alguns apresentadores faziam com os números de audiência antigamente. Tal comemoração ao feito alcançado mostra a importância que a TV tem dado as redes sociais, e como a velha mídia massiva tem encontrado na pós-massiva uma aliada e um medidor de repercussão.

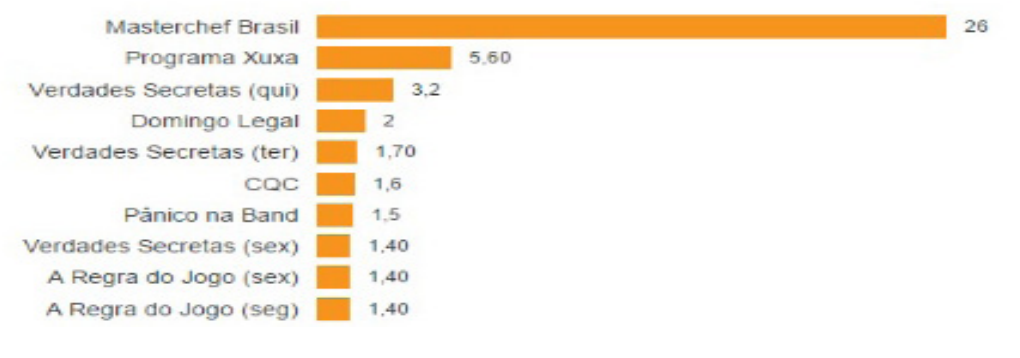

Gráfico 1: Visualizações de tweets sobre o programa, em milhões, entre 7/9 e 13/9. Fonte: Ibope Media
O protagonismo do Twitter também pode ser avaliado pela presença de personalidades com muitos seguidores que foram convidados para, ao vivo, comentarem a atração. Toda essa estratégia deu ao reality o título de programa mais comentado da semana, como mostra o Gráfico 1.

Entretanto, apesar de abraçar o Twitter, o enunciador esqueceu-se que o microblog não pode ser direcionado ou mesmo tencionado a elogiar a atração. Por ter apresentado um episódio repleto de falhas, como um 'ao vivo' que era parcialmente gravado, além de ter demorado muito para anunciar o vencedor, foram recorrentes os tweets com críticas ao programa, como mostra a Figura 3.

Mesmo com a demora em anunciar o vencedor, uma revelação surpreendeu a todos: o vencedor seria revelado primeiro no Twitter e, depois, na televisão. Neste momento, a primeira tela tornou-se indubitavelmente a tela do computador ou do celular, visto que seria nestes suportes que todos saberiam primeiro o resultado. Tratou-se de uma parceria de mídia entre a Band e a empresa de telefonia TIM, conforme Figura 4.

Tal postagem foi compartilhada mais de 36 mil vezes pelos usuários, além de que, em uma decisão comercial, o perfil do MasterChef Brasil logo publicou vários tweets com mensagens de patrocinadores. Ou seja, quem entrou na página para saber o vencedor, precisou passar por uma série de anúncios para ter acesso à informação desejada.

Portanto, o reality em questão foi um exemplo, além de pioneiro, na forma de usar as redes sociais e fomentar a Social TV. Mesmo com alguns tropeços, como o fato de ter chamado "personalidades" já pouco próximas do público e ter usado uma linguagem um tanto quanto datada nos tweets, o MasterChef Brasil reconhe- 


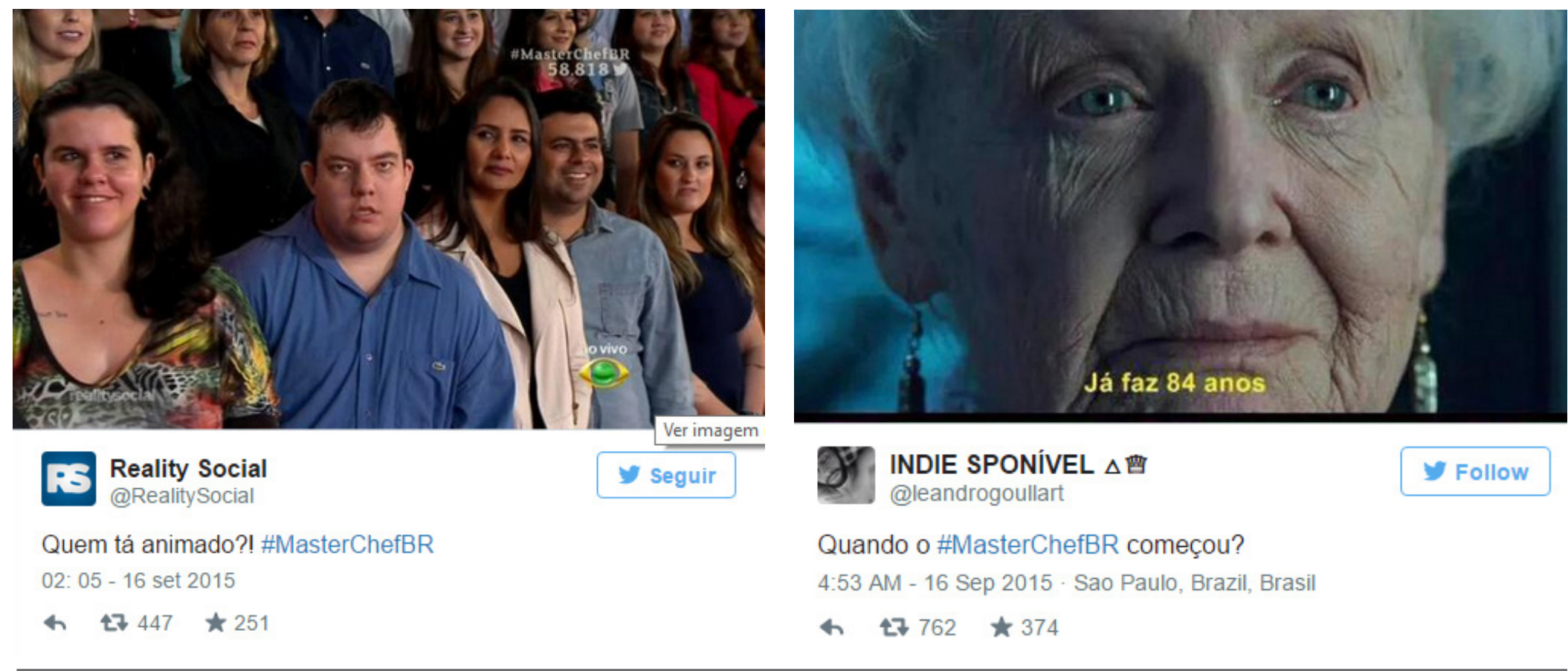

Figura 3: Tweets com críticas à atração Fonte: Twitter.com

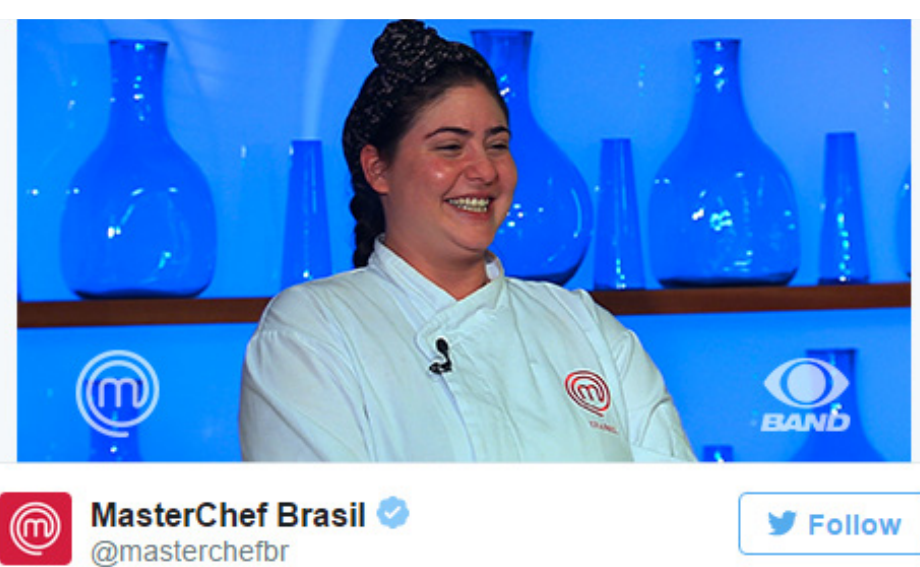

Para tudo! A @TIMBrasil tem a honra de anunciar que o troféu do \#MasterChefBR vai para a Izabel! Parabéns! lo/lo/ o/ 5:11 AM - 16 Sep 2015

4 $2736,060 \star 38,783$

Figura 4: Tweet que anunciou o vencedor da atração Fonte: Twitter.com ceu e abraçou o Twitter não somente como aliado, mas como parte integrante do enredo da atração. A ideia de anunciar o vencedor através do microblog, além de ter trazido ganhos financeiros ao programa - vide que foi patrocinada -, recompensou os usuários por estarem comentando, apropriando e divulgando (mesmo que involuntariamente) o show.

\section{Apontamentos finais}

É notável como o MasterChef tornou-se um exemplo pioneiro de Social TV ao tornar-se uma mídia propagável. O programa percebeu o potencial de seu conteúdo como gerador de conversações a partir da reconfiguração de seus textos de mídia. Logo, fortaleceu e valorizou sua comunidade nicho ao nutri-la constantemente. Um dos meios de visualizar tal valorização foram as alusões e comemorações em relação às menções que o progra- ma conquistava no Twitter. Como destacado anteriormente, tais menções foram utilizadas como parâmetros de sucesso, que anteriormente era mensurado através da pontuação dos índices de audiência.

O grande trunfo do programa, porém, foi fornecer um empoderamento único àqueles que acompanhavam a transmissão ao vivo ao mesmo tempo em que acompanhavam as publicações no Twitter. Tal público teve o poder da informação em primeira mão. Tiveram o privilégio de serem os primeiros a saber a grande notícia que motivou toda a realização do programa: o vencedor.

Poder, interação e socialização foi alcançado por meio da reconfiguração e do espalhamento do conteúdo. O programa soube utilizar os princípios fundamentais da propagabilidade, percebendo que seu sucesso estava para além da relação entre público e televisão. Seu sucesso também dependia de sua atuação nas redes sociais. Já que aquilo que não se propaga morre, podemos afirmar que o MasterChef está mais vivo do que nunca.

\section{Referências}

BAND. Band contrata revelação do MasterChef Brasil. 2015. Online. Disponível em: <http://goo.gl/ggUZ5c>. Acesso em: 23 jan. 2016.

\section{BARBOSA, Lívia; CAMPBELL, Colin. Cultura, consumo e} identidade. Rio de Janeiro: FGV, 2006.

BBC. MasterChef. 2015. Online. Disponível em: <http:// www.bbc.co.uk/masterchef>. Acesso em: 22 set. 2015.

BULKELEY, William. Ten breakthrough Technologies. MIT Technology Review, Maio, 2010. Disponível em: <http:// 
www.technologyreview.com/lists/technologies/2014/>. Acesso em: 20 out. 2014.

CASTELLS, Manuel. A sociedade em rede. São Paulo: Paz e Terra, 2000.

CESAR, Pablo; GEERTS, David. Understanding social TV: a survey. European Community's Seventh Framework programme, 2012. Disponível em: <http://homepages.cwi.nl/ garcia/material/nem-summit2011.pdf>. Acesso em: 19 out. 2014.

CORRÊA, Elizabeth Saad; COUTINHO, Marcelo Lima. O impacto das mídias sociais nas empresas informativas: transformações no processo produtivo. In: BRITTOS, Valério Cruz. (Org). Digitalização e práticas sociais. São Leopoldo: Editora Unisinos, 2009. pp. 23-42.

FECHINE, Yvana. Elogio à programação: repensando a televisão que não desapareceu. In: CARLÓN, Mario; FECHINE, Yvana (Orgs). 0 fim da televisão. Rio de Janeiro: Confraria do Vento, 2014. pp. 114-131.

HARBOE, Gunner. In search of social television. In: CESAR, Pablo; GEERTS, David; CHORIANOPOULOS, Konstantinos. Social interactive television: Immersive shared experiences and perspectives. IGI Global: Pensilvânia, 2009.

IBOPE MEDIA. Rankings. 2015. Online. Disponível em: <http://www.ibopemedia.com/conteudo/dados-rankings/ittr/>. Acesso em: 26 set. 2015.

JENKINS, Henry; GREEN, Joshua; FORD, Sam. Cultura da conexão: criando valor e significado por meio da mídia propagável. São Paulo: Aleph, 2014.
JOHNS, Mark. Two screen viewing and social relationships. Exploring the invisible backchannel of TV viewing. In: Proceedings cultural attitudes towards communication and technology 2012. Murdoch: Murdoch University, 2012. Disponível em: <http://sammelpunkt.philo. at:8080/2159/>. Acesso em: 20 out. 2014.

LEMOS, André. Cibercultura. Tecnologia e vida social na cultura contemporânea. Porto Alegre: Sulina, 2010.

MAFFESOLI, Michel. 0 tempo das tribos: o declínio do individualismo. São Rio de Janeiro: Forense Universitária, 1998

MAINGUENEAU, Dominique. A propósito do ethos. In: MOTTA, Ana Raquel; SALGADO, Luciana (Orgs). Ethos discursivo. São Paulo: Contexto, 2008.

MÉDOLA, Ana Sílvia Lopes Davi; SILVA, Elissa Schpallir. Segunda tela: interatividade, conteúdo extra e socialização. In: Colóquio mídia e tecnologia. Bauru, 2013. Disponível em: <http://www.faac.unesp.br/Home/Pos-Graduacao/MestradoeDoutorado/TelevisaoDigital/elissa. pdf $>$. Acesso em: 19 Out. 2014

MONTPETIT, Marie-José; KLYM, Natalie; BLAIN, Emmanuel. The future of mobile TV: when mobile TV meets the internet and social networking. In: Mobile TV customizing content and experience. London: Springer, 2010.

PADIGLIONI, Cristina. Masterhef se despede ensinando como engajar a audiência no Twitter. Estadão. 2015. Online. Disponível em: <http://cultura.estadao.com.br/ noticias/televisao,masterchef-se-despede-ensinando-como-engajar-audiencia-via-twitter,1762109>. Acesso em: 22 set. 2015.
PRIMO, Alex. A TV interativa chegou no Twitter. In: Dossiê Alex Primo. 2010. Online. Disponível em: <http:// alexprimo.com/2010/04/28/a_tv_interativa_chegou_ no_twitter/>. Acesso em: 20 out. 2014.

PROULX, Mike; SHEPATIN, Stacey. Social TV. How marketers can reach and engage audiences by connecting television to the web, social media, and mobile. New Jersey: John Wiley \& Sons, Inc. 2012.

ROSE, Frank. The art of immersion. How the digital generation is remaking Hollywwod, Madison Avenue, and the way we tell stories. New York: WWNorton \& Company, 2011

SCHATZ, Raimund; BAILLIE, L.; FRÖHLICH, P.; GRECHENIG, T. "What Are You Viewing?" Exploring the Pervasive Social TV Experience. In: Mobile TV customizing content and experience. London: Springer, 2010. pp.255-290.

SCOLARI, Carlos A. O tempo da "hipertelevisão". [6 de março, 2012]. São Paulo: Observatório de Imprensa. Entrevista concedida a Calor Tourinho.

. This is the end? As intermináveis discussões sobre o fim da TV. In: CARLÓN, Mario; FECHI$\mathrm{NE}$, Yvana (Orgs). 0 fim da televisão. Rio de Janeiro: Confraria do Vento, 2014. pp. 34-53.

TANNER, Christy. The Value of Social TV Impressions. In: TVNextConference. 2013. Online. Disponível em: $\quad<\mathrm{http}: / /$ issuu.com/tvguidemarketing/docs/socialtvimpressions? mode $=$ window\&backgroundColor=\%23222222>. Acesso em: 20 out. 2014. 
TOFFLER, Alvin. A terceira onda. São Paulo: Editora Record, 1980.

VERÓN, Eliseo. Semiótica come sociosemiótica. Intervista a Eliseo Verón. In: SCOLARI, Carlos; BERTETTI, P. (eds). Mediamerica. Semiótica e analisi dei media a America Latina. Torino: Cartman Edizioni, 2007.

VOLLMER, Christopher; PRECOURT, Geoffrey. Sempre Ligado!: propaganda, marketing e mídia em uma era controlada pelo consumidor. Porto Alegre: Bookman, 2010.

ZWAANEVELD, Jarno. Comparing Social TV approaches: a look into enjoyment, presence and awareness. $\mathbf{1 1}^{\text {th }}$ student conference on IT, Enchede June 29th 2009. University of Twente, Faculty of electrical engineering, Mathematics and computer science.

\section{Notas}

1 Doutorando no Programa de Pós-graduação em Comunicação Social da Pontifícia Universidade Católica do Rio Grande do Sul (Av. Ipiranga, 6681, Partenon, Porto Alegre/RS, Brasil, CEP: 90619-900). E-mail: mateusdvilela@gmail.com.

2 Doutoranda do Programa de Pós-graduação em Ciência da Comunicação da Universidade do Vale do Rio dos Sinos (Av. Unisinos, 950, São Leopoldo/RS, CEP 93.022-000). E-mail: tauanamwj@hotmail.com.

3 O teórico acredita que tribos são microgrupos dentro da massificação que crescem de forma perene. "A metáfora da tribo permite dar conta do processo de desindividualização, da saturação da função que lhe é inerente, e da valorização do papel que cada pessoa é chamada a representar dentro dela" (Maffesoli, 1998, p.8).

4 Para Vollmer e Precourt (2010, p. 187), "não há mais tempo ocioso na propaganda, na mídia e no marketing [...]. A cada segundo é estabelecida uma conexão com um consumidor em qualquer lugar do mundo. Portanto, os anunciantes, as empresas de comunicação e as agências de propaganda precisam estar sempre ligados", porque seus consumidores estão.

5 Samplear é "utilizar trechos de registros sonoros anteriormente realizados para montar uma nova composição (quase sempre musical) por meio de um aparelho chamado sampleador. Gravar e processar sons (previamente gravados) por meio de um sampleador para conseguir outros. Montar uma composição ou arranjo musical com uso desse instrumento" (DIClONARIOINFORMAL, online, 2015).

6 Do original: Not long ago we were spectators, passive consumers of mass media. Now, on YouTube and blogs and Facebook and Twitter, we are media. No longer content in our traditional role as couch potatoes, we approach television shows, movies, even advertising as invitations to participate as experiences to immerse ourselves in at will.

7 Do original: The springboard that propelled the idea of second screen applications as a companion for TV is based on a simple principle: we are naturally curious human beings who are compelled to feed that curiosity. When we are connected to a second screen while we watch TV, we have instant access to search an infinite amount of information about the program you're watching and thus help to satisfy our natural curiosity.

8 Significa estragar, adiantar algum evento futuro de uma série ou filme.

9 É o último episódio de uma temporada.

10 É quando uma série entra em recesso, normalmente devido a algum feriado em que as emissoras norte-americanas exibem programação especial.

11 É o primeiro episódio de uma temporada.

12 Disponível em: <http://www.bbc.co.uk/masterchef>. Acesso em: 22 Set. 2015

13 Disponível em: <http://cultura.estadao.com.br/noticias/televisao,masterchef-se-despede-ensinando-como-engajar-audiencia-via-twitter,1762109>. Acesso em: 22 Set. 2015

14Disponível em: <http://cultura.estadao.com.br/noticias/televisao,masterchef-se-despede-ensinando-como-engajar-audiencia-via-twitter,1762109>. Acesso em: 22 Set. 2015

15 Disponível em: <http://entretenimento.band.uol. com.br/masterchef/2015/>. Acesso em: 23 jan. 2016. 